\title{
Correction: Screening of cancer tissue arrays identifies CXCR4 on adrenocortical carcinoma: correlates with expression and quantification on metastases using ${ }^{64} \mathrm{Cu}$-plerixafor PET
}

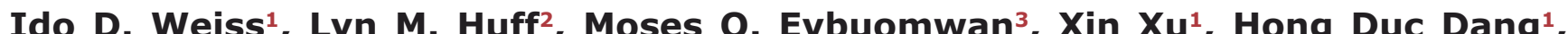
Daniel S. Velez ${ }^{1}$, Satya P. Singh ${ }^{1}$, Hongwei H. Zhang ${ }^{1}$, Paul J. Gardina ${ }^{4}$, Jae-Ho Lee $^{5}$, Liza Lindenberg ${ }^{6}$, Timothy G. Myers ${ }^{4}$, Chang H. Paik ${ }^{5}$, David S. Schrump, Stefania Pittaluga ${ }^{3}$, Peter L. Choyke ${ }^{6}$, Tito Fojo ${ }^{2}$ and Joshua M. Farber ${ }^{1}$

\footnotetext{
${ }^{1}$ Laboratory of Molecular Immunology, National Institute of Allergy and Infectious Diseases, National Institutes of Health, Bethesda, MD, USA

${ }^{2}$ Medical Oncology Branch, Center for Cancer Research, National Cancer Institute, National Institutes of Health, Bethesda, MD, USA

${ }^{3}$ Laboratory of Pathology, Center for Cancer Research, National Cancer Institute, National Institutes of Health, Bethesda, MD, USA

${ }^{4}$ Genomic Technologies Section, Research Technologies Branch, National Institute of Allergy and Infectious Diseases, National Institutes of Health, Bethesda, MD, USA

${ }^{5}$ Radiopharmaceutical Laboratory, Nuclear Medicine Division, Radiology and Imaging Sciences, Clinical Center, National Institutes of Health, Bethesda, MD, USA

${ }^{6}$ Molecular Imaging Program, Center for Cancer Research, National Cancer Institute, National Institutes of Health, Bethesda, MD, USA

7 Thoracic Epigenetics Section, Thoracic and GI Oncology Branch, Center for Cancer Research, National Cancer Institute, National Institutes of Health, Bethesda, MD, USA

Published: October 02, 2018
}

Copyright: Weiss et al. This is an open-access article distributed under the terms of the Creative Commons Attribution License 3.0 (CC BY 3.0), which permits unrestricted use, distribution, and reproduction in any medium, provided the original author and source are credited.

This article has been corrected: On page 73395, the following sentences have been updated to read, "Dosimetry for ${ }^{64} \mathrm{Cu}-$ plerixafor calculated from this single patient gave an Effective Dose of $0.283 \mathrm{rem} / \mathrm{mCi}$, and a total of $2.43 \mathrm{rem}$ from the dose of $8.6 \mathrm{mCi}$. The organs that contributed the most to the Effective Dose were the liver and bone marrow (0.0606 and 0.0760 $\mathrm{rem} / \mathrm{mCi}$, respectively)".

Similar to results in mice, the liver had the highest uptake of the tracer, with unbound tracer excreted through the kidneys $[31,32]$. Significant uptake was also seen in organs of the immune system, including spleen, vertebral bodies (bone marrow), and lymph nodes (Figure 4 and Supplementary Figure 6). Of additional interest, uptake of ${ }^{64} \mathrm{Cu}$-plerixafor was absent from a number of vertebral bodies in the thoracolumbar spine that were within the region of prior radiation therapy (Figure 4 and Supplementary Figure 6). Dosimetry for ${ }^{64} \mathrm{Cu}$-plerixafor calculated from this single patient gave an Effective Dose of 0.283 $\mathrm{rem} / \mathrm{mCi}$, and a total of $2.43 \mathrm{rem}$ from the dose of $8.6 \mathrm{mCi}$. The organs that contributed the most to the Effective Dose were the liver and bone marrow ( 0.0606 and $0.0760 \mathrm{rem} / \mathrm{mCi}$, respectively). PET/CT sections (Figure 4B) showed variable uptake in the multiple pulmonary nodules.

Original article: Oncotarget. 2017; 8:73387-73406. https://doi.org/10.18632/oncotarget.19945 